\title{
In vitro radical scavenging activity of short arm octopus added kimchi and its anti-atherogenic effects in Apo E KO mice
}

\author{
M. Kim ${ }^{1}$, K. Jung ${ }^{1}$, M. S. Jang ${ }^{2}$, J. Lee ${ }^{1}$, J. S. Han ${ }^{1}$ and Y. O. Song ${ }^{1}$ \\ ${ }^{1}$ Department of Food Science and Nutrition and Kimchi Research Institute, Pusan National University, Busan, Korea \\ and ${ }^{2}$ Food and Safety Research Center, National Fisheries Research \& Development Institute, Busan, Korea
}

Kimchi is a Korean traditional fermented vegetable. It usually served as a side dish. The functional property of kimchi has been studied extensively, in particular with lipid lowering and anthi-atherogenic properties ${ }^{(1)}$. Seafood is often added to the kimchi to make taste better. In this study, short arm octopus rich in n-3 polyunsaturated fatty acids (PUFA) and amino acid taurine ${ }^{(2)}$ is added to the kimchi and it's radical scavenging activity and anti-atherogenic properties were studied in the comparison of ordinary Korean cabbage kimchi.

Short arm octopus added kimchi was fermented at 4C until pH of kimchi reached $4 \cdot 3 \pm 0 \cdot 1$. Ethanol extracts of freeze-dried kimchi were used for the examination of radical scavenging activities, in vitro. For the animal study, pagan's rodent atherogenic diet containing $10 \mathrm{~g} \%$ of freeze-dried Korean cabbage kimchi (control) or short arm octopus added kimchi (SK) were provided to the apo E KO mice for 8 weeks.

$\mathrm{IC}_{50}$ for DPPH, hydroxyl and superoxide anion of SK were significantly lowered, compared with the control ( $\left.p<0 \cdot 05\right)$. Plasma and hepatic triglyceride concentrations for the mice fed SK decreased and their fatty streak lesion size was also significantly reduced $(p<0.05)$. It seems that n-3 PUFA in short arm octopus present as approximately $60 \%$ to the total fatty acids is responsible for TG lowering effects. Triglyceride (TG) lowering effects of $n-3$ fatty acids are well established ${ }^{(3)}$. Hepatic TG synthesis might be suppressed by n-3 fatty acid which subsequently reduced plasma TG concentration via diminution of very low density of protein (VLDL) synthesis. Plasma total cholesterol and LDL-cholesterol concentration of SK group decreased but the differences were not significant.

\begin{tabular}{|c|c|c|c|c|}
\hline & \multicolumn{2}{|l|}{ Control } & \multicolumn{2}{|l|}{ SK } \\
\hline & Mean & SD & Mean & SD \\
\hline \multicolumn{5}{|l|}{ Plasma lipids (mg/dL) } \\
\hline Triglyceride & $120 \cdot 50$ & $16 \cdot 18$ & $76 \cdot 25^{*}$ & 29.51 \\
\hline Total cholesterol & 1228.53 & 101.06 & 1074.03 & 177.98 \\
\hline LDL cholesterol & 1207.57 & $100 \cdot 21$ & $1038 \cdot 17$ & 173.43 \\
\hline HDL cholesterol & 17.78 & 1.17 & 18.03 & 1.67 \\
\hline \multicolumn{5}{|l|}{ Hepatic lipids (mg/g tissue) } \\
\hline Triglyceride & $40 \cdot 98$ & 8.68 & $24.85^{*}$ & $5 \cdot 19$ \\
\hline Total cholesterol & 7.25 & 1.48 & 6.65 & 1.08 \\
\hline TC/HDLC & $70 \cdot 34$ & 3.95 & $59.63^{*}$ & 9.40 \\
\hline Lesion area ( $\%$ of whole aorta) & 33.08 & $9 \cdot 28$ & $19.33^{*}$ & $2 \cdot 30$ \\
\hline
\end{tabular}

$n=6$ each group. ${ }^{*}$ Data between two group are significantly different with student's t-test at $p<0 \cdot 05$.

In conclusion, in addition of short arm octopus to Korean cabbage kimchi seems to increase health benefits further, in particular, anti-atherogenic effects that has been already reported from Korean cabbage kimchi.

This work is supported by the Korean Institute of Planning \& Evaluation for the Technology in Food, Agriculture Forestry \& Fisheries (\# 311032)

1. Kwon MJ, Song YO, Song YS. (1997) J. Korean Soc. Food Sci. Nutr. 26, 507-513.

2. Im GS (2009) National Fisheries Research \& Development Institute. 2, 116-119, 150-153.

3. Kim HJ, Takahashi M, Ezaki O. (1999) THE JOURNAL OF BIOLOGICAL CHEMISTRY 274, 25892-25898. 